Borneo Journal of Sciences and Technology, Volume 1, Issue 1, Pages: 09-14

DOI: https://doi.org/10.35370/bjost.2019.1.1-03

e-ISSN: 2672-7439

(C) 2018, UCTS Publisher.

Submitted: 19 September 2018

Accepted: 21 September 2018

Published: 31 January 2019

\title{
Bakery Science of Bread and the Effect of Salt Reduction on Quality: A Review
}

\author{
Naili Nahar ${ }^{1}$, Iffah Nadhira Madzuki², Nur Baitul Izzah ${ }^{3}$, Shahrim Ab Karim ${ }^{1}$, Hasanah M. Ghazali ${ }^{1}$, \\ Roselina Karim ${ }^{1}$
}
${ }^{1}$ Faculty of Food Science and Technology, Universiti Putra Malaysia, 43400 Serdang, Selangor, Malaysia
${ }^{2}$ Faculty of Engineering Technology, Universiti Malaysia Perlis, 02600 Arau, Perlis, Malaysia
${ }^{3}$ Food Safety and Quality Division, Ministry of Health Malaysia, Jalan Persiaran Perdana, Precinct 3, 62675 Putrajaya, Malaysia

\begin{abstract}
Salt or sodium chloride is widely used in most homemade dishes or processed foods. It can be considered as a crucial ingredient because, without adding salt most dishes or food products may have less flavor, become tasteless and not appetizing. The addition of salt can provide salty taste or can even mask the bitter taste. It is also widely used as a preserving agent and can increase product's shelf life. Bread is widely consumed and serves as a staple food for certain countries. Not only that, bread is one of the world's oldest foods and is said to be the largest contributor of salt in our diet. While bread is believed to supply the major percentage of daily salt intake, reduction of salt in this product can assist in reducing the consumption of salt in human's diet. Salt is also found to have detrimental impact on human health as it can cause cardiovascular diseases. Nevertheless, the salt reduction in bread is not easy to apply as salt play important roles in bread-making and its reduction can affect the quality of bread. Salt in bread has been observed to improve dough-making process, enhances the flavor of bread and produces nice brown colour of the bread's crust through Maillard reaction. Besides that, salt also helps in improving the texture, decreasing staling and increasing the microbial shelf life of the bread. This article explains the bakery science of bread by discussing the effect of salt reduction on bread quality.
\end{abstract}

Keywords: culinary science, bakery technology, bread rheology, healthy diet, sodium chloride

\section{INTRODUCTION}

Salt or sodium chloride $(\mathrm{NaCl})$ is a common and important ingredient in food products worldwide. According to Man [1], salt is formed through the ionic combination of sodium ion and chloride ion and for every $2.54 \mathrm{~g}$ of salt consumed, it will yield $1 \mathrm{~g}$ of sodium. Salt has been viewed as a food preservative and protects human from the microbial pathogen in foods for ages ago [2]. Over the last few years, excessive salt intake has been an important issue and is related to various chronic diseases. Gibson et al. [3] and American Institute of Baking (AIB) International [4] stated that excessive salt intake results in hypertension and may increase the risk of cardiovascular diseases (CVD) such as heart attack and stroke. Therefore, people have become more aware of the adverse effects of excessive salt intake and they are demanding for healthier foods. Bread is grouped as the staple food worldwide, therefore, salts present in bread is related to the heart disease.

The regulatory bodies also expanded some efforts to overcome this problem by establishing or limiting the amount of daily salt intake. The World Health Organization [5] recommends 5g of salt per day as a worldwide guideline while the Food Safety Authority of Ireland [6] recommends salt intake of $6 \mathrm{~g}$ daily. Consumption of bread regularly may increase daily intake of sodium as bread supply about $30 \%$ from the recommended daily intake (RDI) for salt [7]. Thus, it is recommended to reduce the amount of salt in bread [8]. An international organization known as World Action on Salt and Health (WASH) was established in 2005 to advice on the bad effects of $\mathrm{NaCl}$ in foods to the world. WASH consists of expert members from 80 countries. WASH is working closely with the governments and industry to reduce the amount of salt used in restaurant, catered and manufactured foods [2]. Bread is one of the world's oldest foods and is said to be the largest contributor of salt in the United Kingdom (UK) diet according to the National Diet and Nutrition Survey (NDNS) [9]. This explains why many efforts were done to reduce salt content in bread. However, salt has several functional properties which highly contribute to the quality and safety of the bread products [10]. Salt 


\section{Bakery Science of Bread and the Effect of Salt Reduction on Quality: A Review}

play important roles in processed food's texture, sensory, handling, manufacturing, and shelf life, making processed foods as the main source of daily dietary sodium intake.

\section{EFFECT ON DOUGH DEVELOPMENT}

Dough development is one of the most important process in bread-making besides the baking process. The technological impact of salt on bread quality can be observed through the bread-making process. The main processes of bread-making include mixing, proofing and baking. The first step in making bread is the mixing of ingredients to develop dough with unique viscoelastic properties during the proofing (fermentation) stage. During this stage, the development of gluten network will occur and will determine the dough behavior. During dough development, it has been found that salt plays some major roles, such as retaining the gas holding capability in the gluten network [10]. Bread quality is dependent on the dough produced at this time, where it changes in the protein structure occur and incorporation with carbon dioxide produced during fermentation may give impact to the texture and flavor of the bread [11]. During dough development, the addition of salt could strengthen gluten network structures of dough as the addition of salt can produce larger protein network and more fibrous strands $[12,10]$. However, in the presence of salt, the development of this fibrous network will take more time to develop and can only be fully developed at the end of the mixing process. This is due to the reduction in hydration rate which results in longer proofing time for fermentation. This is consistent with the findings by Beck et al. [13] where the addition of salt requires a longer time for fermentation and can reduce the fermentation rate. On the other hand, Doyle [2] stated that salt helps in gluten network formation with good extensibility by controlling the hydration of glutenin and gliadin protein. Salt also increases the extensibility of the dough by enabling the gluten to trap small air bubble and thus, high quality bread can be produced [12].

An optimal amount of salt must be determined to produce a gluten network with good stability. Furthermore, it has been reported that the effect of salt on dough and bread quality is flour dependent. McCann and Day [12] showed that after the addition of salt, low protein flour shows an increase in the strength of dough and slower relaxation time compared to high protein flour. Loaf volume, dough relaxation time and strain hardening of the low protein flour are increased as the amount of salt added to the flour increased. These findings explain the function of salt in improving low protein flour as the low protein flour will produce a weaker gluten network in the absence of salt. Dough with a reduced amount of salt often had excessive fermentation where yeast produces too much carbon dioxide $\left(\mathrm{CO}_{2}\right)$, and lead to poor texture and open grain in the bread [14]. The omission of salt will lead to the production of more $\mathrm{CO}_{2}$. On the other hand, the presence of salt could change the environment of yeast growth to be less favorable, thus reducing the quantity of $\mathrm{CO}_{2}$ being produced. Bread with less salt has been found to have higher volume of dough and requires less time to achieve maximum dough height $[13,10]$. Even though reduction of salt can produce larger loaf volume, the loaf produced is characterized to have larger diameter of gas bubbles and a smaller number of air cells.

A research done by Lynch et al. [10] studying on the effect of different levels of salt on bread quality concluded that salt reduction from $1.2 \%$ to $0.6 \%$ and $0.3 \%$ did not lead to significant differences in terms of extensibility and resistance to extension of dough. In contrast, dough with no salt showed $26 \%$ and $21 \%$ reduction in both characteristics, respectively. Reduction of salt is usually able to produce dough with more $\mathrm{CO}_{2}$ but less salt produces weak gluten structure. Thus, the dough cannot hold the $\mathrm{CO}_{2}$ gas and then causing the reduction of the amount of $\mathrm{CO}_{2}$ retained in the dough. However, McCan and Day [12] found that the volume of dough increased with increasing amounts of salt. The difference between these findings could be due to variation in formulation, dough mixing time, proofing and baking condition.

\section{EFFECT ON BREAD FLAVOUR}

Salts influences the flavor of the bread. Bread baked without salts has a bland taste [15]. Sodium salts such as sodium chloride and monosodium glutamate affect the flavor of the foods by enhancing their flavors [2]. Sodium and lithium were found to be the only cations that are primarily salty. While potassium and calcium ions are also salty, they also have "metallic" and "bitter" after-tastes which are not desirable to consumers [2]. Often, $\mathrm{NaCl}$ is used to mask bitter flavor in foods [16].

According to Kilcast and den Ridder [17], 25\% of the Caucasian population are non-tasters (insensitive toward normal amounts of bitter compounds), while $25 \%$ are supertasters (very sensitive to bitter compounds). Decreasing the amount of salt in foods will affect the supertasters, which make the foods appear unpalatable and insipid to them. Water activity and salt are related as salt helps in concentrating the flavor molecules in solution [18]. A study conducted by Lynch et al. [10] 


\section{Bakery Science of Bread and the Effect of Salt Reduction on Quality: A Review}

showed that bread containing $0 \%$ and $1.2 \%$ of salts are clearly distinguished by the sensory panelists. The panelists described that bread without salt as yeasty, acidic and sour. Miller and Hoseney [15] also reported that bread with $0 \%$ salt has an insipid taste. Sosa et al. [19] had tested seven samples of French bread with salt content ranging from $0.6 \%-4.6 \%$ on 100 consumers. Results showed that more panelists prefer bread with $2.4 \%$ salt, which exceeds the $1.8 \%$ amount of salt in common bread.

\section{EFFECT ON BREAD COLOUR}

The brown color of bread is associated with the Maillard reaction in the baking process through reaction between free reducing sugars and proteins. The absence of salt produces bread with lighter brown colored crust, as the result of the reduction in Maillard reaction. In order for Maillard reaction to happen, there must be enough amounts of free reducing sugars and proteins. According to Belz et al. [20], reducing the amount of salt will increase yeast activity in the dough as salt has the ability to control the growth of yeast. Sugar is needed for the growth of yeast; therefore, yeast activity will reduce the availability of free sugars for Maillard reaction [20]. Excessive growth of yeast will lead to poor color of the bread. According to Sluimer [21], at the initial stage of the baking process, the temperature increased up to $100^{\circ} \mathrm{C}$ and is maintained as long as there is moisture at the outer layer of the bread's surface. Maillard reaction starts when the temperature rises to more than $110^{\circ} \mathrm{C}[22]$.

\section{EFFECT ON BREAD TEXTURE}

The texture of bread is important to the acceptance of consumers. Texture can be evaluated in a number of ways such as texture analysis profile and sensory testing [20]. According to Lynch et al. [10], salt helps in strengthening and improving the gluten network of the dough, which helps in producing a more even crumb structure. Salt in the dough helps to stabilize gluten and prevent stickiness of the dough [2]. McCann and Day [12], demonstrated that increasing the level of $\mathrm{NaCl}$ has an impact on increasing the strain-hardening and relaxation of the bread dough, thus producing more volume and even bread structure. Sensory evaluation as assessed by trained panelists showed that the presence of $1.2 \%$ of salt in bread had a higher score for density appearance of the crumb compared to the $0.6 \%$ of salt [10]. As salt concentration decreases, yeast activity increases, resulting in higher volume of bread. However, insufficient amount of salt within the dough develops weaker protein network with low gas retention capability. This will result in the bread produced to have uneven texture and low volume. In contrast, Lynch et al., [10] found that the hardness of bread is not dependent on the amount of salt as there is no significant difference after stored for 2 to 50 hours. Nevertheless, only bread with no added salt was identified to have unacceptable hardness after 120 hours of storage. During the baking process, crumb and crust structures may develop. The quality of crumb was found to be affected by the amount of salt $[12,13]$. The comparison between $0 \%$ and $4 \%$ of salt content in bread showed that there is a difference of about $40 \%$ in crumb firmness after they were stored for 24 hours. This showed that the crumb firmness reduces with the reduction of salt content. The reduction of crumb firmness is also related to the enlargement of loaf volume [13]. The presence of salt can increase firmness because the addition of salt can accelerate the formation of cross-link between starchstarch and starch-protein [23].

The rheology of bread dough can also be determined by measuring the storage module ( $\left.\mathrm{G}^{\prime}\right)$ where it is used to measure elasticity of material. Another rheological parameter, the loss modulus (G") is used to measure the viscosity of bread dough material. Reducing the amount of salt has an effect on G' of dough rheology [10]. The reduction of salt content from $1.2 \%$ to $0.6 \%$ showed a significant increase in $G$ ' however, there is no significant difference with G". This result also has good agreement with that reported by McCann and Day [12]. Thus, salt reduction in bread can affect the elasticity of the dough but does not affect its viscosity. Salt is found to have an effect on the rheology of wheat dough as the $\mathrm{NaCl}$ is able to form sodium and chloride ions where it will compete for water and then cause the wheat protein to hydrate. Hydrated wheat protein cannot hold much water causing free water to increase and then change the rheology of dough [24]. The G' of dough can also be affected by quality and protein content of the flour. The high protein dough (13.5\% of protein content) have higher G' than the lower protein of dough $(9 \%$ of protein content) even with a constant amount of salt [12]. On the other hand, good quality flour is reported to have higher $G^{\prime}$ than poor quality as stated by Khatkar et al. [25].

\section{EFFECT ON BREAD SHELF LIFE}

Salt has been used to preserve foods for a long time. In bread, salt also acts as a preservative besides contribution to flavor. Staling and retrogradation of bread are related to the moisture content of bread. It was found that water migration from crumb to the 


\section{Bakery Science of Bread and the Effect of Salt Reduction on Quality: A Review}

crust is related to the amount of salt presents in the bread [10]. Staling is perceived by dry bread texture due to extended storage, but the mechanism is not simply due to evaporation and it involves complex mechanism. However, staling phenomenon can be summarized due to water activity $\left(a_{w}\right)$ and the distribution of water inside the bread. Bread staling is likely to exist because of starch and gluten modifications, which contribute highly to the retrogradation of the starch [26]. Salt reduces water migration from crumb to crust by holding the water molecules in the bread structure, thus, resulted in a more hydrated environment for the bread which causes staling to occur at a lower rate compared to bread without salt [23]. A study conducted by Beck et al. [13], showed that low crumb staling is highly related to the increased amount of $\mathrm{NaCl}$. This is due to the fact that large $\mathrm{Na}^{+}$ions are entrapped in the molecules compared to the small $\mathrm{H}^{+}$ions; leading to less recrystallization of the starch molecules.

Microbial shelf stability is also affected by the existence of salts in the food products [27]. Reduction in $\mathrm{NaCl}$ level has been found to result in an increase in the number of microbial colony growth [28]. Salt preserves bread by reducing the $a_{w}$ through osmotic pressure in bread environment system [2]. Microbial growth occurs faster in foods with high moisture content. The use of higher concentration of salt produces higher osmotic pressure which causes bread cells to lose water to the environment, and thus retarding the microbial growth [29]. Thus, foods with higher water content are more prone to spoilage bacteria because of the higher $\mathrm{a}_{\mathrm{w}}$. Smith et al. [30] reported that the $\mathrm{a}_{\mathrm{w}}$ for bread is ranged between 0.96 - 0.98. The preservative effect of salt works by lowering the $\mathrm{a}_{\mathrm{w}}$ of the bread. Therefore, the growth of spoilage microbial can be prevented.

High salt level increases the time for microbial growth of some pathogens such as Escherichia coli, Salmonella and Clostrodium botulinum [2]. A study by Samapundo et al. [28] on the effect of different levels of salt, which are $0 \%, 2 \%, 4.2 \%$ and $6.4 \%$ on the growth of Penicillium roqueforti var. carneum $(P$. roqueforti) and Aspergillus niger (A. niger) found that there was a decrease in growth for these microorganisms as the salt level was increased started from $2 \%$. Samapundo et al. [28] also had tested four types of potential salt replacers which are magnesium sulphide $\left(\mathrm{MgSO}_{4}\right)$, potassium chloride $(\mathrm{KCl})$, magnesium chloride $\left(\mathrm{MgCl}_{2}\right)$ and calcium chloride $\left(\mathrm{CaCl}_{2}\right)$ on the growth of $P$. roqueforti and A. niger. Based on this study, the presence of $\mathrm{NaCl}$ or $\mathrm{MgCl}_{2}$ led to the slowest colony growth rates and delayed lag phase of the organisms. Generally, both of these salts are the largest microbial inhibitors of $P$. roqueforti and $A$. niger. Salt acts as preservative in bread, hence reducing the amount of salt will require full or partial replacement of $\mathrm{NaCl}$.

\section{CONCLUSION}

Generally, the reduction of salt level in bread is a good effort to control the daily sodium intake which is known to be a major contributor to several chronic diseases. Recently, cardiovascular diseases (CVD), hypertension, and coronary diseases are related to the high amount of salts intake [31]. However, as salt is one of the essential ingredients in bread-making, its reduction will lead to deterioration of the bread's quality such as its texture, flavor, color, and shelf life. Based on these facts, it can be concluded that salts play many important roles in improving bread quality and safety.

It is a big challenge to the bread industry when salt is reduced in the bread products. This is because, salt is cheap, and any replacement will incur a high cost with new testing and new technology [32]. Salt in bread are relatively low, but people consumed more of this group of foods which contributes $35 \%$ to $50 \%$ of the sodium consumption [33]. In order to reduce salt intake daily, it is suggested that people should add more food varieties in their diets such as rice, noodles, potatoes, fruits, and vegetables instead rely too much on bread as the main carbohydrate sources. Therefore, one of the solutions to reduce salt consumption is by reducing bread intake. Another solution to reduce the salt consumption in bread is by conducting further research to obtain the optimum amount of salt, which can be done by using a statistical and mathematical technique such as Response Surface Methodology (RSM). The best bread formulation with the desired quality can be produced using RSM, where multiple samples with a large variation of salt content can be analyzed and computed.

\section{REFERENCES}

[1] Man, C. (2007). Technological Functions of Salt in Food Products. In D. Kilcast \& F. Angus (Eds.), Reducing Salt in Foods: Practical Strategies (pp. 157-173). Cambridge, UK: Woodhead.

[2] Doyle, M. E., \& Glass, K. A. (2010). Sodium Reduction and its Effect on Food Safety, Food Quality, and Human Health. Comprehensive Reviews in Food Science and Food Safety, 9(1), 44-56.

[3] Gibson, J., Armstrong, G., \& Mcllveen, H. (2000). A case for reducing salt in processed foods. Nutrition \& Food Science, 30(4), 167173. 


\section{Bakery Science of Bread and the Effect of Salt Reduction on Quality: A Review}

[4] American Institute of Baking (AIB) International (2008). Sodium and salt: Health concerns and regulatory status. Retrieved December 4, 2013, from https:// www. aibonline.org/ researchandtechnical/ white papers / Sodium-Jan2008.pdf

[5] World Health Organization. (2003). Diet, nutrition and the prevention of chronic diseases. World Health Organization technical report series (Vol. 916).

[6] Food Safety Authority of Ireland. (2005). Salt and health: Review on the scientific evidence and recommendations for public policy in Ireland.

[7] Girgis, S., Neal, B., Prescott, J., Prendergast, J., Dumbrell, S., Turner, C., \& Woodward, M. (2003). A one-quarter reduction in the salt content of bread can be made without detection. European Journal of Clinical Nutrition, 57(4), 616-620.

[8] Food Standards Agency (2018). Salt. Retrieved July 8, 2018, from https:// www. food.gov.uk /business-guidance/salt

[9] Lennox, A., Olson, A., \& Gay, C. (2011). National diet and nutrition survey. Headline Results from Years, 2(1), 2009-2009. Retrieved from

http://www.foodafactoflife.org.uk/attachments/ 8921d124-960e-4f68d4b026f4.pdf

[10] Lynch, E. J., Dal Bello, F., Sheehan, E. M., Cashman, K. D., \& Arendt, E. K. (2009). Fundamental studies on the reduction of salt on dough and bread characteristics. Food Research International, 42(7), 885-891.

[11] Dobraszczyk, B., \& Morgenstern, M. (2003). Rheology and the breadmaking process. Journal of Cereal Science, 38(3), 229-245.

[12] McCann, T. H., \& Day, L. (2013). Effect of sodium chloride on gluten network formation, dough microstructure and rheology in relation to breadmaking. Journal of Cereal Science, 57(3), 444-452.

[13] Beck, M., Jekle, M., \& Becker, T. (2012). Impact of sodium chloride on wheat flour dough for yeast-leavened products. II. Baking quality parameters and their relationship. Journal of the Science of Food and Agriculture, 92(2), 299-306.

[14] Matz, S. A. (1992). Cookie and cracker technology. Van Nostrand Reinhold. Retrieved from

https://www.springer.com/la/book/9780442308 926

[15] Miller, R. A., \& Hoseney, R. C. (2008). Role of salt in baking. Cereal Foods World, 53(1), 4-6.

[16] Breslin, P. A. S., \& Beauchamp, G. K. (1995).
Suppression of Bitterness by Sodium: Variation Among Bitter Taste Stimuli. Chemical Senses, 20(6), 609-623.

[17] Kilcast, D., \& Den Ridder, C. (2007). Sensory issues in reducing salt in food products. Reducing Salt in Foods, 201-220.

[18] Costa-Corredor, A., Serra, X., Arnau, J., \& Gou, P. (2009). Reduction of $\mathrm{NaCl}$ content in restructured dry-cured hams: Post-resting temperature and drying level effects on physicochemical and sensory parameters. Meat Science, 83(3), 390-397.

[19] Sosa, M., Flores, A., Hough, G., Apro, N., Ferreyra, V., \& Orbea, M. M. (2008). Optimum Level of Salt in French-Type Bread. Influence of Income Status, Salt Level in Daily Bread Consumption, and Test Location. Journal of Food Science, 73(8), S392-S397.

[20] Belz, M. C. E., Ryan, L. A. M., \& Arendt, E. K. (2012). The Impact of Salt Reduction in Bread: A Review. Critical Reviews in Food Science and Nutrition, 52(6), 514-524.

[21] Sluimer, P. 2005. Principles of breadmaking: functionality of raw materials and process steps. St. Paul: American Association of Cereal Chemists Inc. p 224.

[22] Mondal, A., \& Datta, A. 2008. Bread baking-a review. Journal of Food Engineering, 86(4), 465-474.

[23] He, H., \& Hoseney, R. (1990). Changes in bread firmness and moisture during long-term storage. Cereal Chem, 67(6), 603-605.

[24] Jekle, M., \& Becker, T. (2011). Dough microstructure: Novel analysis by quantification using confocal laser scanning microscopy. Food Research International, 44(4), 984-991.

[25] Khatkar, B. S., Bell, A. E., \& Schofield, J. D. (1995). The dynamic rheological properties of glutens and gluten sub-fractions from wheats of good and poor bread making quality. Journal of Cereal Science, 22(1), 29-44.

[26] Gray, J. A., \& Bemiller, J. N. (2003). Bread Staling: Molecular Basis and Control. Comprehensive Reviews in Food Science and Food Safety, 2(1), 1-21.

[27] Doerry, W. (1990). Water activity and safety of bakery products. Am Inst Baking Res Dept Tech $B, 12(6), 1-6$.

[28] Samapundo, S., Deschuyffeleer, N., Van Laere, D., De Leyn, I., \& Devlieghere, F. (2010). Effect of $\mathrm{NaCl}$ reduction and replacement on the growth of fungi important to the spoilage of bread. Food Microbiology, 27(6), 749-756.

[29] Yigit, A., \& Korukluoglu, M. (2007). The effect of potassium sorbate, $\mathrm{NaCl}$ and $\mathrm{pH}$ on 
the growth of food spoilage fungi. Annals of Microbiology, 57(2), 209-215.

[30] Smith, J. P., Daifas, D. P., El-Khoury, W., Koukoutsis, J., \& El-Khoury, A. (2004). Shelf Life and Safety Concerns of Bakery ProductsA Review. Critical Reviews in Food Science and Nutrition, 44(1), 19-55.

[31] He, F. J., \& MacGregor, G. A. (2007). Dietary salt, high blood pressure and other harmful effects on health. Reducing Salt in Foods, 1854.

[32] Purdy, J., \& Armstrong, G. (2007). Dietary salt and the consumer: reported consumption and awareness of associated health risks. Reducing Salt in Foods, 99-123.

[33] Beer-Borst, S., Costanza, M. C., PechèreBertschi, A., \& Morabia, A. (2009). Twelveyear trends and correlates of dietary salt intakes for the general adult population of Geneva, Switzerland. European Journal of Clinical Nutrition, 63(2), 155-164. 